\title{
Optimal house elevation for reducing flood-related losses
}

\author{
Siyuan Xian, ${ }^{1}$ Ning Lin, ${ }^{1}$ and Howard Kunreuther ${ }^{2}$ \\ ${ }^{1}$ Department of Civil and Environmental Engineering, Princeton University \\ ${ }^{2}$ Center for Risk Management and Decision Processes, Wharton School, University of \\ Pennsylvania
}

Correspondence to: Siyuan Xian: PhD candidate at the Department of Civil and Environmental Engineering, Princeton University. Email: sxian@ princeton.edu; E223, Equad, Princeton University. Phone: 609-937-3612. Fax: 609-258-2760

Ning Lin: Assistant Professor at the Department of Civil and Environmental Engineering, Princeton University. Email: nlin@ @ princeton.edu

Howard Kunreuther: James G. Dinan Professor and Co-Director at Risk Management and Decision Processes Center, Wharton School, University of Pennsylvania. Email:

kunreuth@wharton.upenn.edu 


\section{Abstract}

FEMA recommends that houses in coastal flood zones be elevated to at least 1 foot above the Base Flood Elevation (BFE). However, this guideline is not specific and ignores characteristics of houses that affect their vulnerability. An economically optimal elevation level (OEL) is proposed that minimizes the combined cost of elevation and cumulative insurance premiums over the lifespan of the house. As an illustration, analysis is performed for various coastal houses in Ortley Beach, NJ. Compared with the strategy of raising houses to 1 foot above BFE, the strategy of raising houses to their OELs is much more economical for the homeowners. Elevating to the OELs also significantly reduces government spending on subsidizing lowincome homeowners through, for example, a voucher program, to mitigate flood risk. These results suggest that policy makers should consider vulnerability factors in developing riskreduction strategies. FEMA may recommend OELs to homeowners based on their flood hazards as well as house characteristics or at least providing more information and tools to homeowners to assist them in making more economical decisions. The OEL strategy can also be coupled with a voucher program to make the program more cost-effective.

Keywords: Optimal elevation level, FEMA, NFIP flood insurance, Affordability, Voucher program 


\section{Introduction}

Among all natural hazards, floods are the most costly, especially in low-lying areas (Kunreuther \& Michel-Kerjan, 2009; Michel-Kerjan, 2015; Michel-Kerjan \& Kousky, 2010; Perry, 2000). The number of Presidential disaster declarations associated with floods in the United States has increased substantially over the past 50 years (Kunreuther, 2015). The increase in coastal population and assets contributes to a rise in damage and economic losses (Pielke Jr., 2008; Aerts et al., 2014). Climate studies predict more intensive storm surge flooding in the future owing to storm activity change and sea level rise (Lin et al., 2012 and 2016; Buchanan et al., 2015) and thus more damage and losses (Lin and Shullman, 2017). Coastal residents can undertake self-protection measures to mitigate the negative impact from the increasing flood hazard in advance, through risk reduction measures (e.g., raising houses) and/or risk transfer (i.e., flood insurance) (Kunreuther and Slovic, 1978; Lewis and Nickerson, 1989; Quiggin, 1992). The marginal return from spending on long-term risk mitigation may be significantly higher than the spending on ex-post recovery (Davlasheridze et al., 2017).

In the US, a homeowner can purchase flood insurance through the National Flood Insurance Program (NFIP) created in 1968 as a partnership between the federal government and local communities. The Federal Emergency Management Agency (FEMA) manages the program and delineates flood zones for local communities and specifies the base flood elevation (BFE) for Special Flood Hazard Areas (SFHA) ${ }^{1}$. The BFE represents the 100-year flood level (i.e. the elevation that has a 1-percent probability of being equaled or exceeded by the flood level in any given year). The American Society of Civil Engineers (ASCE) standard for flood design and

\footnotetext{
${ }^{1}$ The SFHA refers to 100-year flood zones that include A zones (e.g., AE zone, AO zone, etc) and V zones (e.g., VE zone and V1-V30 zones).
} 
construction indicates the minimum requirement for building construction in flood hazard areas that are subject to the building code. Under the regulations of both ASCE $24^{2}$ and NFIP, FEMA requires coastal houses with repetitive losses and/or substantial damage from flood events to be elevated to at least 1 foot above the BFE and recommends all houses in SFHA to be elevated to this level (FEMA, 2011). However, this requirement/recommendation does not provide guidance for homeowners about how many feet exactly their houses should be raised to. The minimum of this requirement, 1 foot above the BFE (also called "1-foot freeboard", FEMA 2014a), may be used as a general mitigation guide by homeowners. Some local engineering companies providing home elevation services also suggest that their clients elevate their homes to the lowest required levels that fulfill the local policy ${ }^{3}$. More importantly, this elevation strategy reflects only the severity of the hazards (through BFE) but not the vulnerability characteristics of the houses. A previous study notes that flood risk should be determined by both flood hazard and house exposure values (Czajkowski et al. 2013). We further argue that house elevation and, more generally, risk mitigation measures should be determined by considering both the flood hazard and the vulnerability/exposure characteristics, such as house value, size, lifespan, and ground elevation.

In addition to the problem with risk reduction requirement, flood insurance in the NFIP is heavily subsidized and does not reflect the actual risk ${ }^{4}$. Recent studies have argued that providing premium discounts misleads homeowners about their risk; instead, the premium should be risk-based and reflect the expected losses (Michel-Kerjan and Kunreuther, 2011;

${ }^{2}$ ASCE 24 refers to the Flood Resistant Design and Construction Standard by ASCE. This standard provides minimum requirements for flood-resistant design and construction of structures located in flood hazard areas. ${ }^{3}$ Personal communication with construction companies by phone in Toms River, New Jersey on Oct 25, 2015.

${ }^{4}$ The significant losses from Hurricane Katrina (2005) led Congress to pass the Biggert-Waters Flood Insurance Reform Act of 2012 (BW-12), which would increase the insurance premiums to reflect the actual risk. However, the Act aroused discussion of affordability issues among low- and moderate-income homeowners. In March 2014, the passage of the Homeowner Flood Insurance Affordability Act (HFIAA-14) delayed the premium increases. 
Kunreuther and Michel-Kerjan, 2011; Kunreuther et al., 2013; National Research Council, 2015; Kunreuther, 2016). Risk-based insurance encourages risk mitigation by rewarding individuals who invest in flood mitigation measures with reduced premium. However, the risk-based, higher insurance premium may induce affordability problems for homeowners who currently pay subsidized premiums (Kunreuther et al., 2013). To address this issue, Kousky and Kunreuther (2013) propose a means-tested voucher program to assist low- and moderate-income homeowners to pay for flood insurance and undertake risk reduction measures such as elevating their houses. Kousky and Kunreuther (2013) show that a voucher program coupled with elevating houses to " 1 -foot freeboard" is often more cost-effective than the voucher subsidizing insurance alone. Here we argue that the voucher program is even more economically effective if the coupled mitigation strategy takes into account house vulnerability characteristics.

We propose that an economically optimal elevation level (OEL) for coastal houses can be estimated through a cost-benefit analysis (CBA). Specifically, the OEL can be calculated as the level that minimizes the sum of the upfront elevation cost and present value of cumulative annual expected losses over the lifespan of a house. As the annual expected loss is the main component of the risk-based insurance premium, OEL also minimizes the sum of elevation cost and cumulated insurance premium. In addition to hazard variables (e.g., BFE), this OEL varies with vulnerability variables such as house characteristics (e.g., house value, size, and ground elevation), lifespan, and discount interest rate, because they affect the elevation cost and total expected future losses/premiums. Homeowners will benefit from applying the OEL as they will pay less overall. When policymakers consider applying a voucher program to address affordability issues, the voucher cost will be reduced if houses are elevated to their OELs because, by definition, OEL generates the lowest total and thus voucher costs. 
In the following sections, we first introduce the calculation of OEL and voucher cost (Section 2). Second, we analyze OEL for three actual houses located in Ortley Beach, NJ, and illustrate how OEL varies with various hazard and vulnerability variables. We also examine OEL for all houses in the AE and VE flood zones in Ortley Beach and compare the economic benefit of the OEL strategy vs. the "1-foot freeboard" strategy at the community scale (Section 3). Then, still using Ortley Beach as a study area, we investigate how OEL plays a role in designing an effective and economical voucher program (Section 4). Finally, we summarize the main findings and propose future research (Section 5).

\section{Methods}

\section{Calculation of $O E L$}

The OEL minimizes the sum of the upfront elevation cost and present value of the cumulative expected annual losses over the lifespan of a house. Let $h^{*}$ be the OEL above the ground; it is defined as:

$h^{*}=\operatorname{argmin}_{h}\left(C(h)+\sum_{t=1}^{S} \frac{1}{(1+r)^{t}} E(h)\right)$

where $C(h)$ is the cost function of house elevation with respect to elevation height $h$, and it can be obtained from FEMA's "Homeowners' Guide to Retrofitting” (FEMA, 2009, 2014a); $E(h)$ is the expected annual loss when the house elevation is $h$ feet above the ground; $t$ represents time and $s$ is the lifespan of the house in years; and $r$ is the discount interest rate.

In this study, we consider a constant expected annual loss $(E(h))$. When effects of climate change and sea level rise on the flood hazard are accounted for, this annual quantity will change 
with time. Eq (1) can be used similarly to calculate the OEL that accounts for these dynamic climate effects, except with $E(h)$ replaced by $E(h, t)$, the time-varying expected annual loss accounting for the temporal variation of the flood hazard and vulnerability (Lin and Shullman, 2017; Gilroy and McCuen, 2012; Ettinger et al., 2016). In contrast, the "1-foot freeboard" strategy depends on a static flood hazard measure and cannot incorporate the temporal evolution of the hazard. Therefore, the OEL formulation, which considers potential losses over the lifecycle of the house, provides a more convenient way to account for the long-term, dynamic climate change effects.

Also, the expected annual loss $(E(h))$ may be replaced by the risk-based annual insurance premium, as the former is the main component of the latter. When homeowners are making elevation decisions, they may consider either the elevation upfront cost and the expected annual damage or the elevation upfront cost and the annual insurance premium if they are required or choose to purchase insurance to transfer the residual risk after mitigating the flood risk. Thus, $E(h)$ may be considered as either the expected annual loss or the risk-based annual insurance premium. (If the effects of climate change are accounted for, $E(h, t)$ can be considered as the time-varying expected annual loss or risk-based annual insurance premium.) In this study, we consider $E(h)$ as the risk-based insurance premium, and it is calculated based on the FEMA flood insurance manual (FEMA, 2014b).

To compare the economic benefit of the OEL strategy vs. the "1-foot freeboard" strategy, we consider their difference in the total cumulative cost of elevation and insurance. We define "saving" as the difference in the total cumulative cost if we elevate a house to 1 foot above BFE compared to its OEL. When the OEL happens to be 1 foot above the BFE, the saving is zero. Otherwise, the saving will always be positive because OEL generates the minimized total cost 
(Eq. 1). Let $h_{l}$ be the height of "1 foot above the BFE" reference to the ground (note that the original BFE value is in reference to NAVD88 5 ). The saving between "1-foot freeboard" and the OEL, $S\left(h_{1}, h^{*}\right)$, is the following:

$S\left(h_{1}, h^{*}\right)=C\left(h_{1}\right)-C\left(h^{*}\right)+\sum_{t=1}^{S} \frac{1}{(1+r)^{t}}\left(E\left(h_{1}\right)-E\left(h^{*}\right)\right)$

where $E\left(h_{1}\right)$ is the annual insurance premium if the house is elevated to 1 foot above BFE and $E\left(h^{*}\right)$ is the annual insurance premium if the house is elevated to its OEL (calculated from Eq. 1). Again, if the effects of climate change are accounted for, $E\left(h_{1}\right)$ is replaced by $E\left(h_{1}, t\right)$ and $E\left(h^{*}\right)$ is replaced by $E\left(h^{*}, t\right)$.

\section{Calculation of Voucher Cost}

As discussed above, OEL may be recommended to the homeowners, and risk-based premium should be charged based on the expected losses. The upfront cost of elevating homes to OELs may be financed with low-interest loans that will be paid back with a specific amount annually. However, low-income homeowners may not be able to afford the combined insurance and loan cost. Kunreuther and Kousky (2014) propose to use vouchers to subsidize part of the combined cost that is above homeowners' affordability based on their annual family income. The voucher is the amount of financial assistance from the government that can be used only in the payment for flood insurance and loan tied to hazard mitigation. Vouchers are defined on an annual basis, to provide direct information for determining the annual governmental budget that needs to be invested in the voucher program. The total voucher cost (the sum of annual voucher

\footnotetext{
${ }^{5}$ NAVD88 is the vertical control datum of orthometric height in the United States of America based on the General Adjustment of the North American Datum of 1988
} 
costs over the lifespan) is minimized if the house is elevated to the OEL, instead of other levels, because the OEL generates the minimized total costs and a low-income homeowner would pay a constant amount based only on income. Therefore, coupling the OEL mitigation strategy with the voucher program is economical for the government.

The annual voucher cost is simply defined as the annual combined cost of insurance and loan minus the homeowner's affordable annual amount (the voucher is zero if the homeowner can afford the integral annual amount). The annual combined cost within the loan length is the annual payment for the loan plus the insurance premium; the annual cost beyond the loan length is the insurance premium alone as the loan has been paid off. Thus, when the house is elevated to a height $h$, the annual voucher cost $V(h, t)$ in year $t$ is:

$$
\begin{cases}V(h, t)=\max \left(0,\left(\frac{C(h)}{\sum_{j=1}^{t_{l}} \frac{1}{(1+l)^{j}}}+\mathrm{E}(\mathrm{h})-\mathrm{k} * \mathrm{~m}\right)\right) & \mathrm{t} \leq t_{l} \\ V(h, t)=\max (0, E(h)-k * m) & t>t_{l}\end{cases}
$$

where $C(h)$ is the total loan amount (equal to the elevation cost) that is paid off by a specific amount annually over the loan length; $t_{l}$ is the loan length, which may be shorter than the lifespan of the house $s\left(0 \leq t_{l} \leq s\right)$; $l$ is the loan interest rate, which is to be determined by the voucher policy and may be lower than the discount interest rate $r$; $k$ is the affordable proportion of the annual income; and $m$ is the annual household income. $E(h)$ is the constant insurance premium we consider in this study; if effects of climate change are accounted for, $E(h)$ is replaced by $E(h, t)$.

To compare the voucher cost of the OEL vs. the "1-foot freeboard" mitigation strategies, we consider "annual voucher saving," or the difference in annual voucher cost if a house is elevated to OEL compared to "1-foot freeboard", denoted by VS, 
$V S(t)=V\left(h_{1}, t\right)-V\left(h^{*}, t\right)$

where $V\left(h_{1}, t\right)$ is the voucher cost in year $t$ if the house is elevated to 1 foot above BFE, and $V\left(h^{*}, t\right)$ is the voucher cost in year $t$ if the house is elevated to its OEL.

\section{Optimal elevation levels}

We investigate OEL in this section. To illustrate the calculation of OEL, we first apply the analysis to three actual houses in a coastal community. Next, we examine the variation of the OEL with various hazard and vulnerability parameters. Then, we calculate the OEL for all houses in the community that are required to purchase flood insurance and quantify the benefit of applying the OELs by calculating the total saving if the houses are elevated to their OELs rather than "1-foot freeboard".

The sample community is Ortley Beach, NJ. The community was severely damaged by coastal floods from superstorm Sandy in 2012. The house information data used in this study, including location, ground elevation, house size, and house value, were collected by a team of students and faculty from University of Notre Dame and Princeton University in an onsite survey three weeks after Sandy. The house information as well as the damage analysis for the community has been published elsewhere (Xian et al. 2015; Hatzikyriakou et al. 2015).

\subsection{OEL for three sample houses}

Table 1 shows the characteristics of the three sample houses. House\#1 and \#2 are within the AE zone with the same BFE of 6 feet above NAVD 88. House \#3 is in the VE zone, much 
closer to the coastline, with a BFE of 10 feet above the NAVD 88. The ground elevation is 5 feet (1 foot below the BFE) for House \#1, 6 feet (on the BFE) for House \#2, and 9 feet (1 foot below the BFE) for House \#3. Figure 1 shows the estimated elevation cost, cumulative insurance premium, and the combined total cost as functions of the elevation height for each of the three houses. Elevation cost depends on the size, foundation type ${ }^{6}$, and elevation height of the house; the elevation cost per foot is the highest for the first two feet and reduces dramatically for higher levels (FEMA, 2009, 2014a). The annual insurance premium, dependent on the height of the lowest structural member of the house relative to $\mathrm{BFE}^{7}$ and other house characteristics including house value, is calculated based on FEMA's flood insurance manual (FEMA, 2014b). The cumulative insurance premium is the sum of present value of the annual insurance premiums over the house lifespan. In these examples, we assume the lifespan of the houses is 30 years and the annual discount rate is $3 \%$. As the elevation height increases, the elevation cost increases and the cumulative insurance premium decreases, with the total cost minimized at the OEL (Eq. 1).

Specifically, for House \#1 (Fig. 1a), the OEL is zero (on the ground). Because the value of this house is relatively low, as the elevation height increases, the insurance premium reduction is smaller than the increase in the elevation cost. From the economic point of view, the house is not recommended to be elevated, but the "1-foot freeboard" (1 foot above the BFE) strategy recommends raising the house by 2 feet. In this case, the OEL does not comply with the FEMA requirement. House \#2 has an OEL of 1 foot above the ground (Fig. 1b). This house has a size similar to House \#1 but a higher value and thus a higher premium. As a result, the reduction in

\footnotetext{
${ }^{6}$ There are mainly two types of foundations in Ortley Beach: crawlspace foundation (the most common type) and the slab-on-grade foundation. Houses with crawlspace foundations are cheaper to elevate. Houses \#1, \#2 and \#3 all have crawlspace foundations.

${ }^{7}$ Height of the lowest structural member relative to BFE refers to the front door elevation minus the BFE. In general, the higher the relative height, the lower the insurance premium. In this study, buildings are assumed to be located on the ground because the study estimates how high the buildings should be elevated from the ground.
} 
the cumulative insurance premium is higher than the increase of elevation cost for the first foot of elevation. It is thus cost-effective to elevate House \#2 by 1 foot, which happens to agree with the "1-foot freeboard" rule. The OEL of Building \#3 is 5 feet above the ground (Fig. 1c). Although House \#3 has a higher ground elevation, it has a higher value and is located in VE zone, and thus it has a much higher insurance premium than the other two houses. Consequently, it is cost-effective to elevate House \#3 to as much as 5 feet above the ground, while the 1-foot freeboard strategy recommends raising the house by only 2 feet above the ground. These examples demonstrate that the economically optimal elevation depends on various hazard and vulnerability parameters; applying the simple "1-foot freeboard" (or, e.g., 2-foot or 3-foot freeboard) rule may result in a much lower or higher level than the optimal.

\subsection{Effects of hazard and vulnerability parameters}

To further illustrate the effects of hazard and vulnerability parameters, we examine the variation of the OELs with all relevant parameters including house characteristics, ground elevation, BFE, lifespan, and annual discount rate. We use House \#2 as an example and study the dependence of OEL on each parameter with the values of other parameters fixed (Figure 2). The patterns of variation of the OEL are similar for other houses.

Figure 2a shows that the larger the house (for a fixed value), the higher the cost of elevation and thus the smaller the OEL. Figure $2 b$ shows that the higher the house value (for a fixed size), the higher the premium and its reduction with elevation and thus the higher the OEL. Figures $2 \mathrm{c}$ and $2 \mathrm{~d}$ show that ground elevation and BFE negatively and positively affect the OEL, respectively. The insurance rate is lower if the ground elevation is higher, and a low insurance 
premium would not motivate a high elevation. Residents living on the high ground may not be better off elevating their houses much higher above the ground. On the other hand, the insurance rate increases with the BFE. It is often economical for homeowners to raise the property to high elevation if they live in a floodplain with a high BFE. Figure 2e shows that the lifespan positively affect OEL; Figure $2 \mathrm{f}$ shows that the discount interest rate negatively affect OEL. Longer lifespan increases the present value of cumulative insurance premium reduction owing to elevation and thus motivates a higher elevation. A higher discount interest rate, however, reduces the present value of the cumulative insurance premium and thus encourages a lower elevation.

\subsection{OEL analysis at the community scale}

To examine the OEL strategy at the community scale, we calculate the OELs for all houses in coastal AE (213 houses) and VE (14 houses) zones (for which flood insurance is required) in Ortley Beach, NJ (Figure 3). The characteristics of these houses are shown in Table 2. For each house, we also calculate the saving, or reduction in total cumulative cost if the house is elevated to OEL compared to 1 foot above the BFE (Eq. 2). The analysis in Section 3.2 shows that the lifespan of the house is an important but uncertain parameter. Thus, here we apply three lifespan scenarios, 30 years (Figure 4), 50 years (Figure 5), and 100 years (Figure 6), for a sensitivity analysis.

To make a direct comparison with the " 1 foot freeboard" strategy, here we show the OEL level relative to the BFE. Figures 4a, 5a, and 6a show that the range of the OELs of the houses in Ortley Beach is between two feet below BFE and four feet above BFE. A great proportion (around 45\%) of the houses have an OEL at BFE for all three lifespan scenarios, while others' 
OELs are either higher or lower than BFE, depending on the relevant parameters, as discussed in the previous section. In general, when houses have a high value but small size and are located in the VE zone, their OELs are much higher than the BFE. On the contrary, when houses have a low value but large size and are located in the AE zone, their OELs are much lower than the BFE. Figures $4 b, 5 b$, and $6 b$ show that the majority of the total cost reduction due to applying OELs are in the range of $\$ 0$ to $\$ 50,000$, but the distributions are associated with heavy tails of large savings up to $\$ 150,000$ (i.e., some homeowners will save a significant amount of money if they elevate their houses to the OEL rather than 1 foot above BFE). About half of the houses can save more than $\$ 10,000$ over the lifespan if they are elevated to OELs.

The lifespan parameter has a significant effect on OELs, while it is irrelevant for the "1foot freeboard" strategy. The distribution of the OELs shifts to higher values relative to the BFE with a larger lifespan. For example, 44 out of the 227 houses have an OEL below BFE if all these houses have a lifespan of 30 years (Figure 4a), while there are only 12 houses with an OEL below BFE if all these houses have a lifespan of 100 years (Figure 6a). The distribution of the reduction in total cost, however, shifts slightly to the lower values when the lifespan increases from 30 to 100 years (Figures 4b, 5b, and 6b). This shift is mainly due to the fact that many low OELs increase to BFE or 1 foot above the BFE if houses have longer lifespans, and thus the reduction in total cost (with OEL vs. "1-foot freeboard") decreases for these houses.

\section{Voucher coupled with OEL}

We apply the voucher analysis to Ortley Beach in this section. We first show the variations of voucher cost with different elevation levels, using the three sample houses in Table 1. Next, 
we investigate the effects of loan length and loan interest rate on the voucher cost using these three sample houses. Then, to quantify the benefit of coupling a voucher program with OELs, we calculate the reduction in voucher cost if houses are elevated to the respective OELs compared to "1-foot freeboard" for all AE and VE zone houses in Ortley Beach.

In addition to the house characteristics used for the OEL calculation, one needs the information about household income to perform the voucher calculation (Eq. 3). Since income information is not publically available, we collected the income information for 24 households using questionnaires that were distributed and collected by the President of the Ortley Beach Voters and Taxpayers Association. The household income for the three sample houses were collected (among the 24 households) and shown in Table 1. To estimate the income for the other houses, we applied a multivariate linear regression model to correlate the household income with the type of the house (primary or secondary) and its property value (from NJ property tax data). The statistical model has an R-square value of 0.64 , based on the collected data. We then applied the model to estimate the household income for the houses missing income data. Supported by information about affordability from the questionnaires, we assume the affordable fraction of income ( $k$ in Eq. 3) is $2 \%$ for all houses.

\subsection{Voucher cost of three sample houses}

Figure 7 shows the variation with the house elevation of annual insurance premium, payment for the loan, homeowner's affordable payment, and voucher cost (Eq. 3), for the three sample houses in Table 1. In these examples, we assume that the loan length $t_{l}$ is the same as the

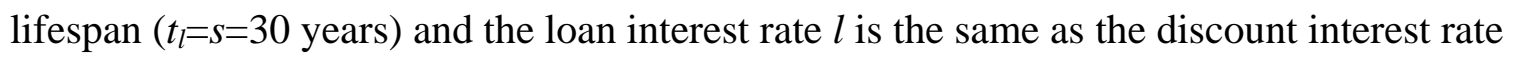


$(l=r=3 \%)$. As the elevation level increases, insurance premium decreases and annual payment for the loan increases. The annual total cost is the sum of the insurance premium and annual payment for the loan (or the insurance premium alone after the loan is paid off). The voucher cost is the annual total cost minus the (constant) affordable amount, and thus the lowest total and voucher costs meet at the same elevation level. Thus, as the OEL minimizes total costs, it also minimize the voucher cost. Therefore, no matter whether the cost is paid totally by the homeowner or partially by the voucher, the OEL of each house is the most cost-effective option.

In these specific cases, if House \#1 is elevated to its OEL, which is zero, it does not need a loan, so the voucher and the homeowner's affordable payment will be combined to pay for the current insurance premium (Fig. 7a). If House \# 2 (Fig. 7b) and House \#3 (Fig. 7c) are elevated to their OELs, the voucher and the homeowner's affordable payment will together pay for the combined cost of the insurance and loan. If the lifespan of these houses is longer than the loan period, these two houses need no voucher assistance after the loan period, as their insurance premium is lower than their affordable payment.

\subsection{Effects of loan interest rate and loan length}

The cost of the voucher depends on the loan length and the loan interest rate, which affect the voucher cost during the loan period. We use the three sample houses elevated to their OELs to illustrate this analysis.

Figure 8 shows how the voucher cost within the length of the loan varies with various loan interest rates $(1 \%, 3 \%, 5 \%$, and $10 \%)$. The voucher cost of House \#1 (Fig. 8a) does not vary because its OEL is zero (no loan payment) and the voucher cost is the difference between the 
current insurance premium and the affordable payment. The annual voucher costs of Houses \#2 (Fig. 8b) and \#3 (Fig. 8c) increase with the increase of the loan interest rate, as the affordable payment is constant ( $2 \%$ of the income). In all three cases, voucher assistance is needed, so the increase of the loan payment is totally covered by the increased voucher cost. In general, however, a relatively high loan interest rate benefits the government, as the high-income homeowners will contribute more. Therefore, it is reasonable to specify a fair loan interest rate (e.g., 2-3\%) and use vouchers as a tool to help low- and medium-income families.

Figure 9 shows how voucher cost varies with various loan lengths $(5,10,15,20,25$, and 30 years). The voucher cost of House \#1 (Fig. 9a) does not vary, as it does not have a loan. The annual voucher costs of the Houses \#2 (Fig. 9b) and \#3 (Fig. 9c) decrease with the increase of the loan length, as the annual total cost decreases with the increase of the loan length while the affordable amount is constant. Note that policy makers should also consider the total voucher cost over the loan length. The longer the loan length, the more the homeowner contributes to the total cost and the less the total voucher cost is. Thus, it is economically beneficial for the government to specify a reasonably long loan length (e.g., 10-30 years).

\subsection{Voucher costs for Ortley Beach}

For a community-level analysis, we calculate the voucher costs for all houses in Ortley Beach with "OEL" and "1-foot freeboard" mitigation strategies, assuming the lifespan of the houses is 30 years, the discount interest rate is $3 \%$, the loan length is 30 years, and the loan interest rate is $3 \%$. Figure 10a shows the distribution of the annual voucher cost if the houses are elevated to their OELs, and Figure 10b show the distribution of the "annual voucher saving," 
which is the increase in the voucher cost if the houses are instead elevated to 1 foot above BFE (Eq. 4). With the OEL elevation strategy, the annual voucher cost for the Ortley Beach houses ranges from $\$ 0$ to $\$ 4000$ (Fig. 10a), and $85 \%$ of the homeowners can afford the insurance and annual payment for the loans and do not need a voucher. If the houses are all elevated to 1 foot above the BFE, the increase in voucher costs for many houses can be as large as over $\$ 2000$ annually (Fig. 10b), and the proportion of homeowners who do not need a voucher reduces to $65 \%$. The sum of the annual voucher costs of the 227 houses in the AE and VE zones in Ortley Beach is $\$ 33,769$ if the houses are elevated to their respective OELs. This number increases to $\$ 125,255$ if the houses are raised to 1 foot above BFE. Thus the total voucher cost for all 227 houses can be reduced by $\$ 91,486$ annually for Ortley Beach if OELs are implemented rather than "1-foot freeboard" strategy. Over the entire loan length (i.e., 30 years), the present value of total voucher cost reduction is $\$ 1,846,961$ (with a $3 \%$ discount rate) for this small community. The difference can be hundreds of millions of dollars if we consider all coastal communities in New Jersey or billions of dollars for the entire U.S. Therefore, we propose that the voucher program should be coupled with an OEL mitigation strategy instead of the "1-foot freeboard" strategy to make it more economical for the government.

\section{Conclusion}

The economic damage from flooding has been dramatically growing in recent decades. Flood risk can be mitigated by a combination of risk reduction measures and insurance coverage. Insurance premiums should reflect the actual risk in order to motivate risk reduction. FEMA requires or recommends coastal houses to be elevated at least to 1 foot above BFE (" 1 -foot 
freeboard"). We argue that an effective mitigation strategy should account for both hazard (partially reflected in BFE) and vulnerability characteristics of a house. In particular, we propose an OEL, at which the sum of upfront elevation cost and cumulative expected losses (or riskbased insurance premiums) over the house's lifespan is minimized.

To solve the affordability issues arising from risk-based insurance pricing, Kousky and Kunreuther (2014) propose a voucher program coupled with elevating houses to FEMA's current guideline of "1-foot freeboard." We further develop the voucher program by coupling it with the OEL-raising strategy. The voucher program is more cost-effective since the voucher cost can be much lower when houses are elevated to OELs instead of other levels. Voucher cost also varies with the loan length and loan interest rate, suggesting that the government should specify reasonable loan lengths and interest rates in the voucher program, considering both short- and long-term benefits and budget constraints.

To illustrate, we applied OEL and voucher analyses to a coastal community, Ortley Beach in NJ. OELs are found to be sensitive to house characteristics and differ for different houses within a flood zone. Over $\$ 10,000$ per structure can be saved for about half of the houses in Ortley Beach over their lifespan if they are elevated to OELs instead of "1-foot freeboard." Some houses (5\%) can save more than $\$ 100,000$. Furthermore, coupling OELs with a voucher program can make the program significantly more economical. For even a small community like Ortley Beach, a present value of $\$ 1,846,961$ can be reduced in voucher cost over a 30 -year life cycle if all houses in the AE and VE zones are elevated to their OELs compared to "1-foot freeboard."

Results of this study reveal that it would be more economically favorable for both homeowners and the government to consider house-level characteristics and apply the OEL 
mitigation strategy for residential houses. This OEL strategy may be written into the homeowners' guidelines for flood retrofit. The voucher program can be coupled with the OELs, requiring that homeowners who want to obtain voucher assistance must raise their homes to the OELs. However, implementing such a policy may take a long time. A more feasible way in the short term is to develop a computer tool that homeowners can use to obtain their OELs and the voucher amounts they need after inputting more specific information (i.e., cost of elevation, insurance premium, household income, and house characteristics). This output information can enable them to make better decisions in home elevation to reduce future flood losses.

Note that there are other indirect and unmeasured benefits of elevating houses (such as protecting life and avoiding rental cost during the evacuation and recovery) that are not accounted for. These benefits may be accounted for by considering risk aversion and expected utility (Cha and Ellingwood, 2012). As a result, it may be beneficial to raise the houses even higher than the OEL calculated in this study. Also, to illustrate the idea of the OEL, in this study we assume that the FEMA insurance premium can reflect the expected losses and we do not consider the effects of climate change and sea-level rise on future losses. However, the OEL formulation can incorporate the temporal variation of flood hazard by replacing the constant expected annual loss (or risk-based premium) with one that changes with time due to climate change and sea-level rise, as discussed in the Methods section. Future research should implement such analysis to estimate OELs that account for these effects. To achieve this goal, one needs to integrate state-of-the-art climate, hurricane, hydrodynamic, inundation, and vulnerability/economic models to better assess the risk under future climate conditions (Lin and Shullman, 2017). The resulting OELs may be significantly higher than the OELs estimated in this study. 
Finally, it is challenging for policy makers to design effective risk communication tools that can motivate coastal residents to elevate their homes and purchase flood insurance. Previous studies found that recent experience of intensive disasters come to one's mind more easily, as explained by the theory of availability bias (Tversky and Kahneman, 1974), and influence people's perceptions towards disaster risk and voluntary flood mitigation behaviors (Botzen et al., 2009; Botzen et al., 2015; Shao et al., 2016, 2017). Future research should examine how to better convey to coastal residents the actual flood risk that may deviate from their past experience, especially in the context of climate change. This step will be crucial for shaping the actual mitigation behaviors of coastal homeowners towards the optical risk reduction strategies such as elevating to OEL as discussed in this paper.

Acknowledgement

This study was supported by National Science Foundation (NSF) grant EAR-1520683. We would like to thank Mr. Paul Jeffrey, the President of Ortley Beach Voters and Taxpayers Association (OBVTA), who helped us to spread and collect the questionnaires among the residents in Ortley Beach, NJ.

\section{References:}

Aerts, J. C. J. H., Botzen, W. W., Emanuel, K., Lin, N., de Moel, H., \& Michel-Kerjan, E. O. (2014). Evaluating flood resilience strategies for coastal Xiamegacities. Science, 344(6183), 473475.

Becker, G., Aerts, J. C. J. H., \& Huitema, D. (2014). Influence of flood risk perception and other factors on risk-reducing behaviour: a survey of municipalities along the Rhine. Journal of Flood Risk Management, 7(1), 16-30.

Botzen, W. J. W., Aerts, J. C. J. H., \& Van Den Bergh, J. C. J. M. (2009). Dependence of flood risk perceptions on socioeconomic and objective risk factors. Water Resources Research, 45(10). 
Botzen, W. W., Kunreuther, H., \& Michel-Kerjan, E. (2015). Divergence between individual perceptions and objective indicators of tail risks: Evidence from floodplain residents in New York City. Judgment and Decision Making, 10(4), 365.

Buchanan, M.K., Kopp, R.E., Oppenheimer, M. and Tebaldi, C., (2015). Allowances for evolving coastal flood risk under uncertain local sea-level rise. Climatic Change, pp.1-16.

Cha, E. J., \& Ellingwood, B. R. (2012). Risk-averse decision-making for civil infrastructure exposed to low-probability, high-consequence events. Reliability Engineering \& System Safety, 104, 27-35.

Crowell, M., Hirsch, E., \& Hayes, T. L. (2007). Improving FEMA's coastal risk assessment through the National Flood Insurance Program: an historical overview. Marine Technology Society Journal, 41(1), 18-27.

Czajkowski, J., Kunreuther, H., \& Michel-Kerjan, E. (2013). Quantifying Riverine and StormSurge Flood Risk by Single-Family Residence: Application to Texas. Risk Analysis, 33(12), 2092-2110.

Davlasheridze, Meri, Karen Fisher-Vanden, and H. Allen Klaiber. The effects of adaptation measures on hurricane induced property losses: Which FEMA investments have the highest returns?. Journal of Environmental Economics and Management 81 (2017): 93-114.

Ettinger, S., Mounaud, L., Magill, C., Yao-Lafourcade, A. F., Thouret, J. C., Manville, V., ... \& Uchuchoque, J. A. L. (2016). Building vulnerability to hydro-geomorphic hazards: Estimating damage probability from qualitative vulnerability assessment using logistic regression. Journal of Hydrology, 541, 563-581.

FEMA. (2009). Homeowner's guide to retrofitting: six ways to protect your home from flooding. FEMA p-312. $2^{\text {nd }}$ edition. Washington, DC.

FEMA (2011) Coastal construction manual: principles and practices of planning, siting, designing, constructing, and maintaining residential buildings in coastal areas. FEMA P-55, Washington. DC.

FEMA (2014a). Homeowner's guide to retrofitting: six ways to protect your home from flooding. FEMA p-312. $3^{\text {rd }}$ edition. Washington, DC.

FEMA. (2014b). Flood insurance manual: Effective. Extracted from: https://www.fema.gov/media-library/assets/documents/93344

FEMA. (2014c). "NFIP rating and the community rating system." $\langle$ https://www.fema.gov/national-flood-insurance-program-community-rating-system〉 (Jul. 2015).

Gilroy, K. L., \& McCuen, R. H. (2012). A nonstationary flood frequency analysis method to adjust for future climate change and urbanization. Journal of Hydrology, 414, 40-48.

Government Accountability Office (GAO). (2013). Flood insurance: More information needed on subsidized policies. 〈http://www.gao.gov/products/GAO-13-607) (Dec. 20, 2014). 
Hatzikyriakou, A., Lin, N., Gong, J., Xian, S., Hu, X., \& Kennedy, A. (2015). Component-Based Vulnerability Analysis for Residential Structures Subjected to Storm Surge Impact from Hurricane Sandy. Natural Hazards Review, 05015005.

Hayes, T. L., and Neal, D. A. (2011). “Actuarial rate review: In support of the recommended Oct 1, 2011, rate and rule changes.” Federal Emergency Management Agency, Washington, DC.

Kousky, C., \& Kunreuther, H. (2014). Addressing affordability in the national flood insurance program. Journal of Extreme Events, 1(01), 1450001.

Kunreuther, H., \& Slovic, P. (1978). Economics, psychology, and protective behavior. The American Economic Review, 68(2), 64-69.

Kunreuther, H., \& Michel-Kerjan, E. (2009). At war with the weather. Massachusetts Institute of Technology.

Kunreuther, H., Michel-Kerjan, E., \& Pauly, M. (2013). Making America more resilient toward natural disasters: A call for action. Environment: Science and Policy for Sustainable Development, 55(4), 15-23.

Kunreuther, H. (2015). The Role of Insurance in Reducing Losses from Extreme Events: The Need for Public-Private Partnerships $\dagger$. The Geneva Papers on Risk and Insurance-Issues and Practice, 40(4), 741-762.

Kunreuther, H. (2016). Reducing Losses From Catastrophes: Role of Insurance and Other Policy Tools. Environment: Science and Policy for Sustainable Development, 58(1), 30-37.

Lewis, T., \& Nickerson, D. (1989). Self-insurance against natural disasters. Journal of Environmental Economics and Management, 16(3), 209-223.

Lin, N., Emanuel, K., Oppenheimer, M., \& Vanmarcke, E. (2012). Physically based assessment of hurricane surge threat under climate change. Nature Climate Change, 2(6), 462-467.

Lin, N., Kopp, R. E., Horton, B. P., \& Donnelly, J. P. (2016). Hurricane Sandy’s flood frequency increasing from year 1800 to 2100. Proceedings of the National Academy of Sciences, 201604386.

Lin, N., \& Emanuel, K. (2016). Grey swan tropical cyclones. Nature Climate Change, 6(1), 106111.

Lin, N., \& Shullman, E. (2017). Dealing with hurricane surge flooding in a changing climate: Part I. risk assessment. Stochastic Environment Research and Risk Assessment. doi: 10.1007/s00477-016-1377-5

Michel-Kerjan, E. O., \& Kousky, C. (2010). Come rain or shine: Evidence on flood insurance purchases in Florida. Journal of Risk and Insurance, 77(2), 369-397.

Michel-Kerjan, E. (2015). We must build resilience into our communities. Nature, 524(7566), 389-389. 
Michel-Kerjan, E and Kunreuther, H. (2011). Reforming flood insurance. Science, 333. 408-409.

National Research Council. (2015). Affordability of national flood insurance program premiums: Report 1, National Academies Press, Washington, DC.

Perry, C. A. (2000). Significant floods in the United States during the 20th century-USGS measures a century of floods: US Geological Survey.

Petrolia, D. R., Landry, C. E., \& Coble, K. H. (2013). Risk preferences, risk perceptions, and flood insurance. Land Economics, 89(2), 227-245.

Pielke Jr, R. A., Gratz, J., Landsea, C. W., Collins, D., Saunders, M. A., \& Musulin, R. (2008). Normalized hurricane damage in the United States: 1900-2005. Natural Hazards Review, 9(1), $29-42$.

Quiggin, J. (1992). Risk, self-protection and ex ante economic value-some positive results. Journal of Environmental Economics and Management, 23(1), 40-53.

Shao, W., Xian, S., Keim, B. D., Goidel, K., \& Lin, N. (2016). Understanding perceptions of changing hurricane strength along the US Gulf coast. International Journal of Climatology. doi: 10.1002/joc. 4805

Shao, W., Xian, S., Lin, N., Kunreuther, H., Jackson, N., Goidel, K. (2017). Understanding the effects of past flood events and perceived and estimated flood risks on individuals' voluntary flood insurance purchase behavior. Water Research, 108 (1): 391-400. doi: 10.1016/ j.watres.2016.11.021.

Tversky, A., \& Kahneman, D. (1973). Availability: A heuristic for judging frequency and probability. Cognitive psychology, 5(2), 207-232.

Xian, S., Lin, N., \& Hatzikyriakou, A. (2015). Storm surge damage to residential areas: a quantitative analysis for Hurricane Sandy in comparison with FEMA flood map. Natural Hazards, 79(3), 1867-1888.

Zhao, W., Kunreuther, H., \& Czajkowski, J. (2015). Affordability of the national flood insurance program: Application to Charleston County, South Carolina. Natural Hazards Review, 04015020. 


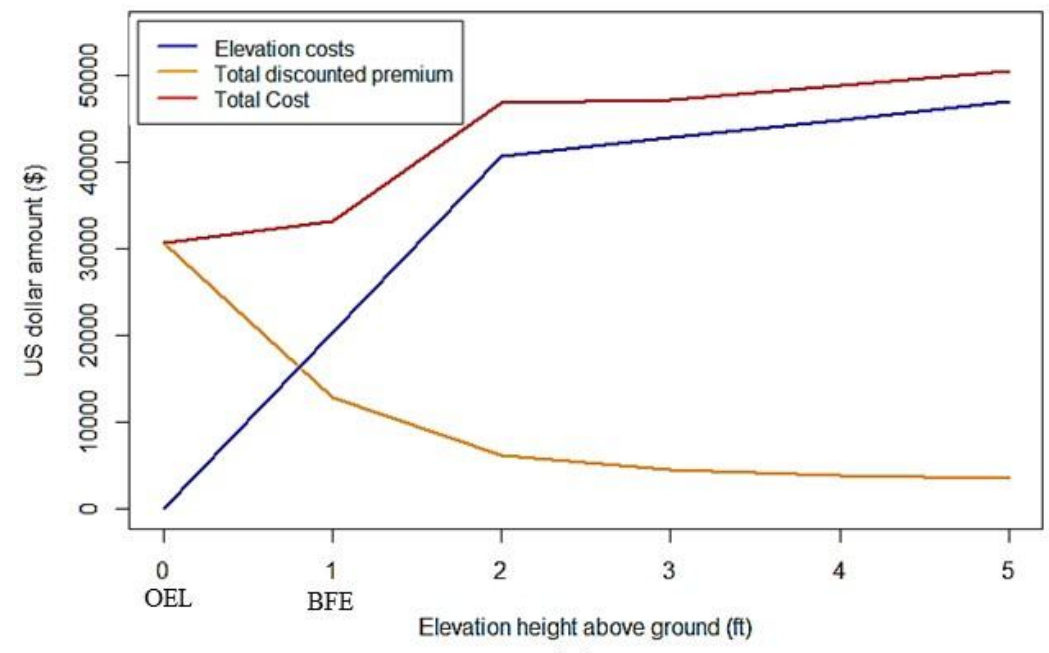

(a)

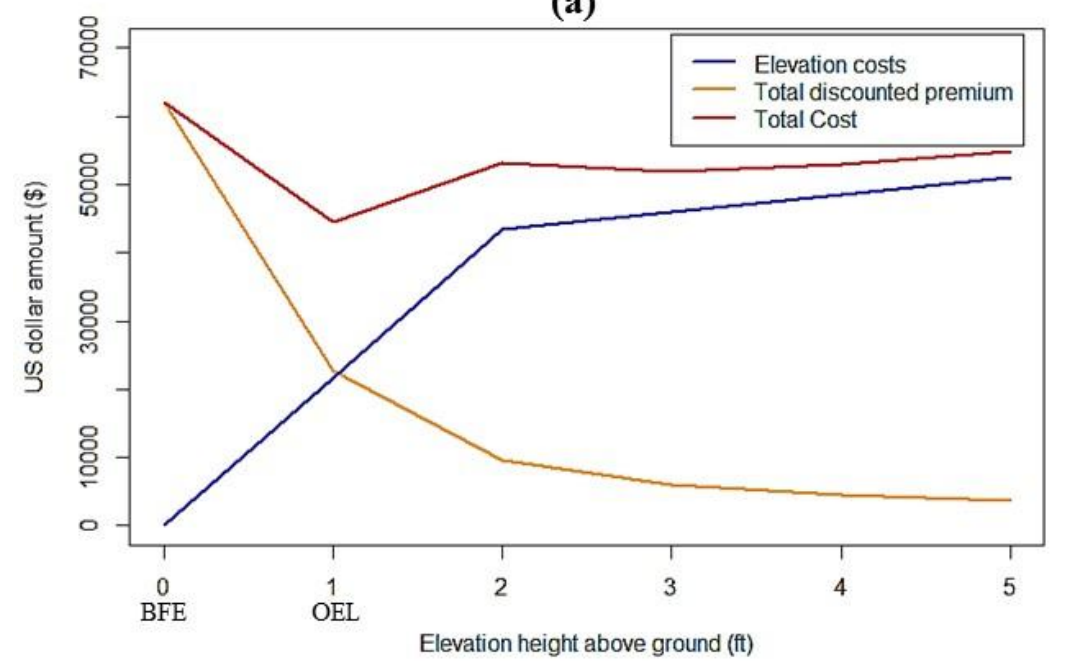

(b)

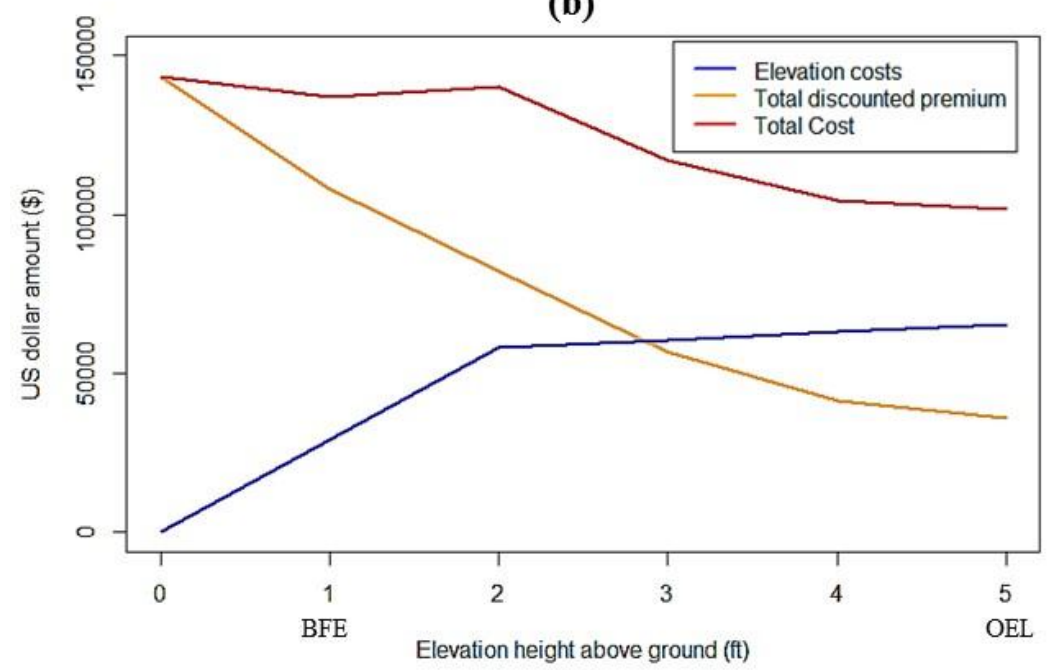

(c)

Figure 1. Analysis of the OEL, at which the cost of elevation and discounted present value of cumulative insurance premiums over the house' lifespan is minimized, for the three sample buildings listed in Table 1: 
(a) House \#1, (b) House \#2, and (c) House \#3. Discount interest rate is 3\%; lifespan of the three houses is 30 years.

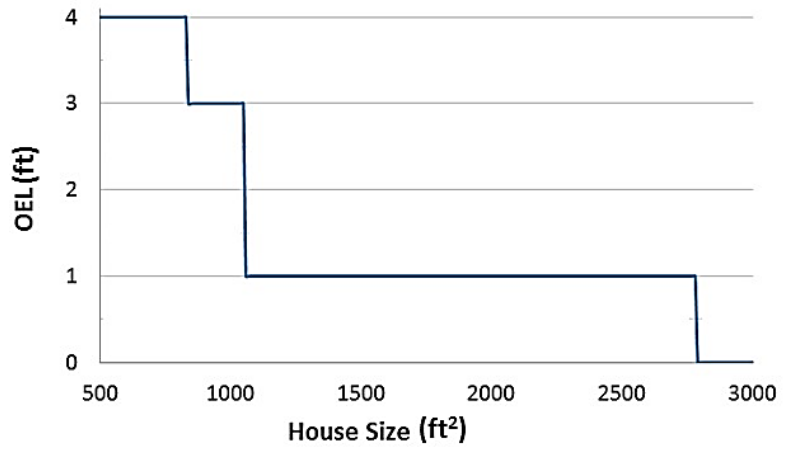

(a)

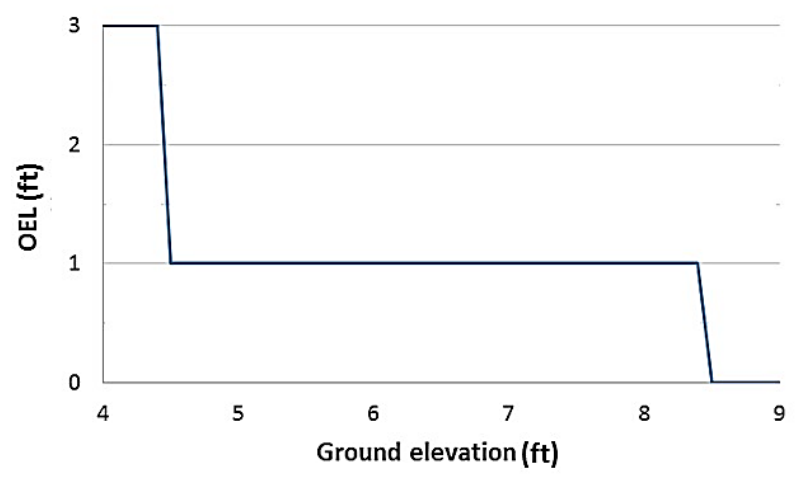

(c)

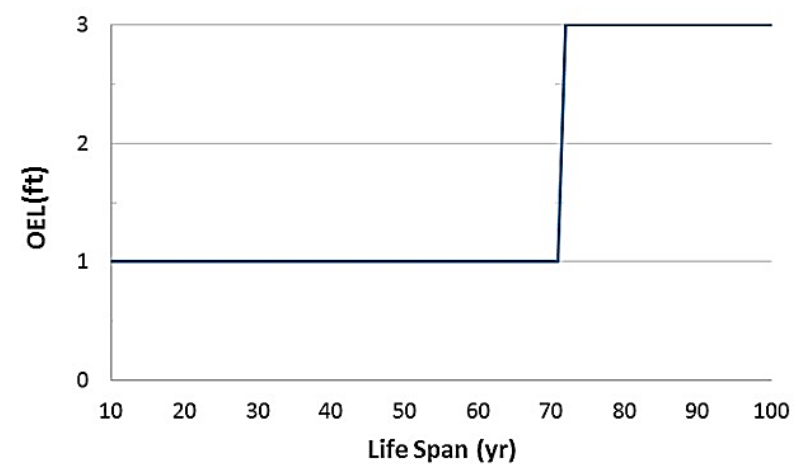

(e)

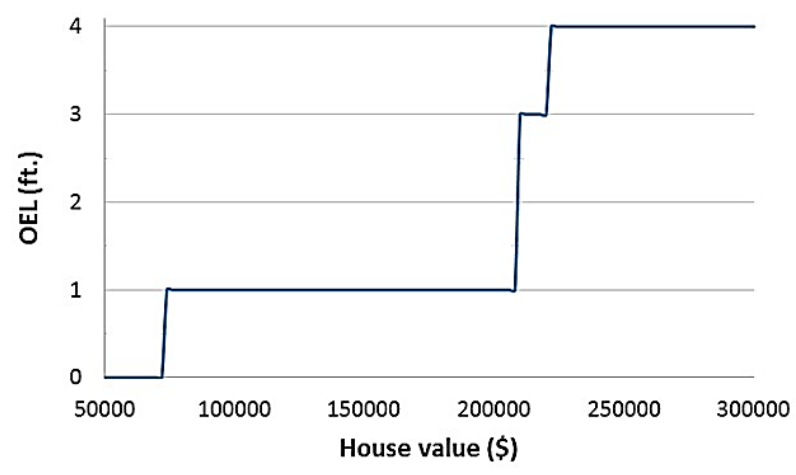

(b)

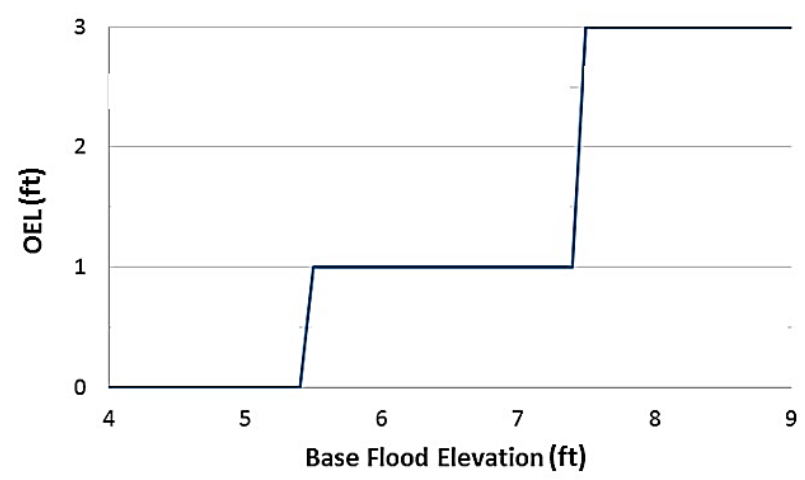

(d)

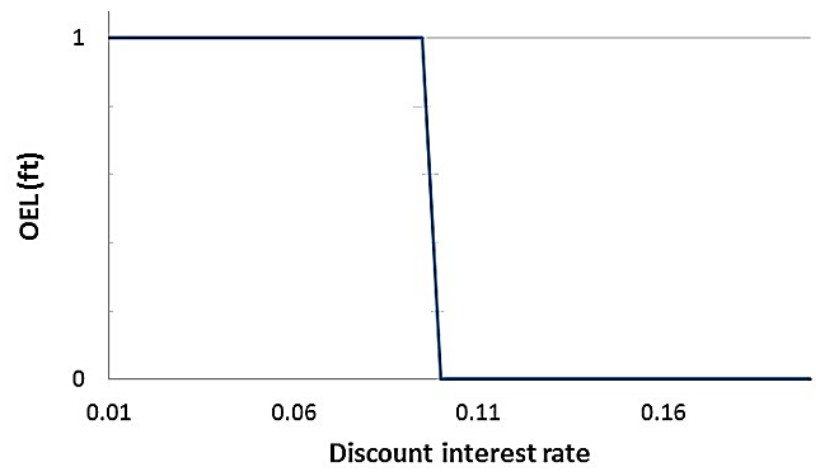

(f)

Figure 2. The OEL of House \#2 as a function of (a) house size, (b) house value, (c) ground elevation;,(d) BFE, (e) house lifespan, and (f) discount interest rate. For each case, all other variables are fixed. 


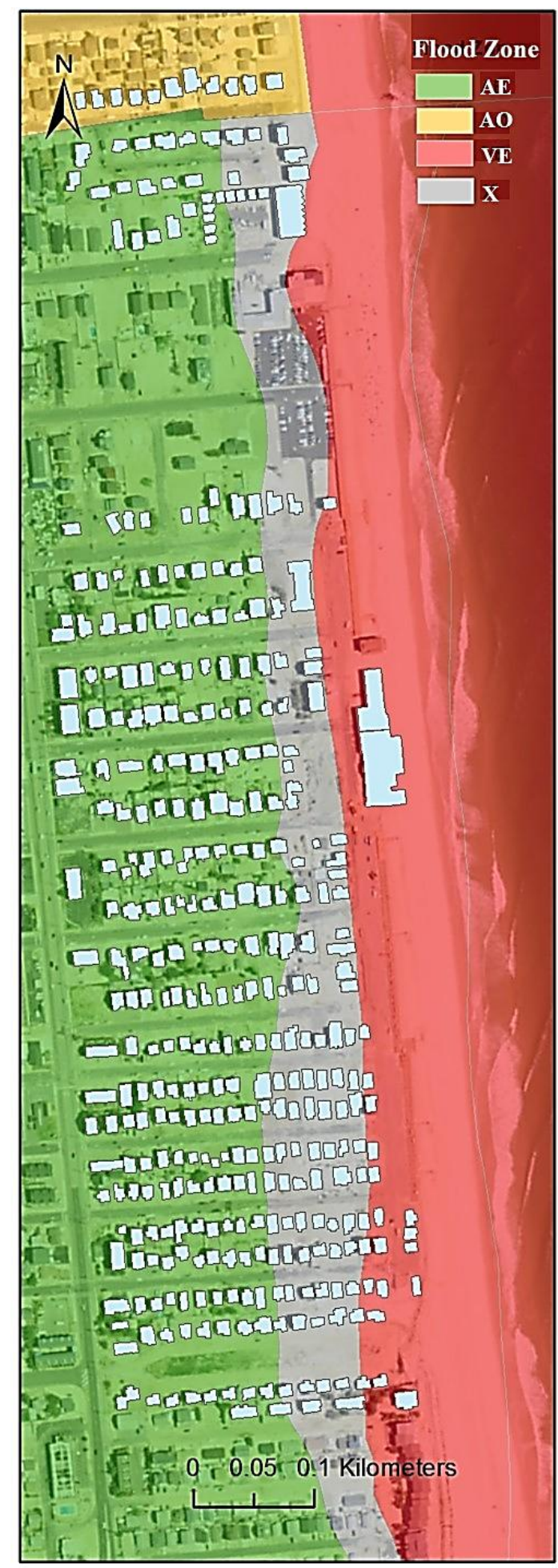

Figure 3. Spatial distribution of residential houses in various flood zones in Ortley Beach, NJ. 

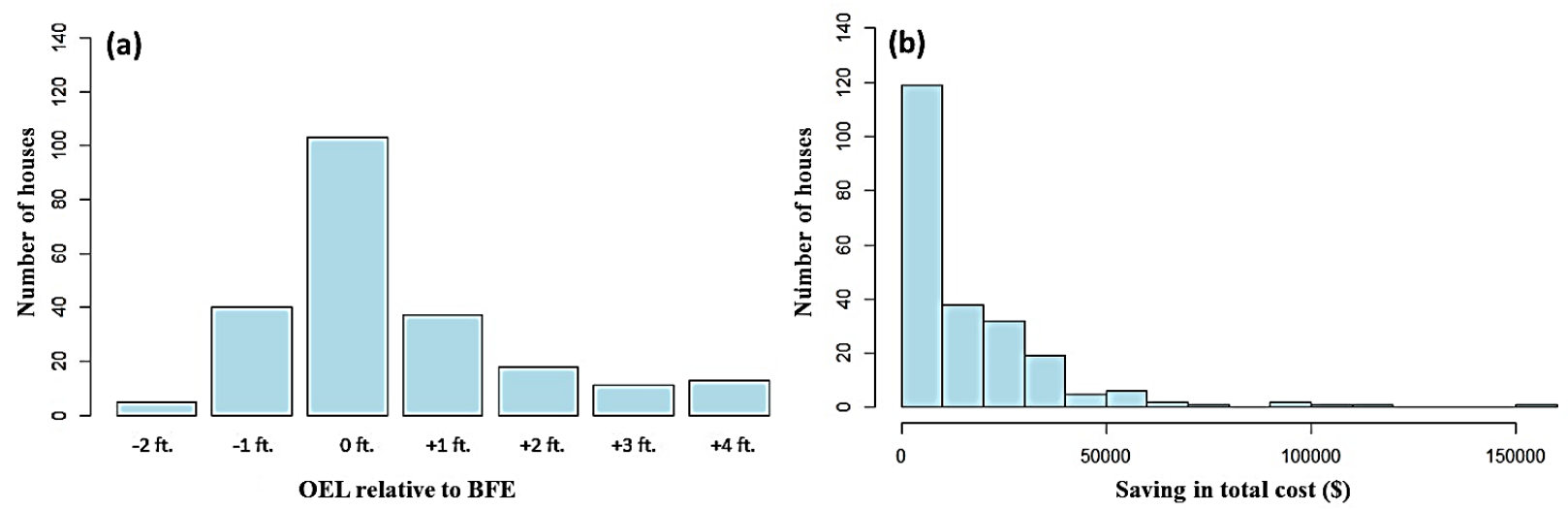

Figure 4. The distribution of (a) OEL and (b) the resulting savings if the house is elevated to OEL compared to 1-foot freeboard, for all houses in the AE and VE zones in Ortley Beach. The assumed discount interest rate is $3 \%$; lifespan of all houses is 30 years.
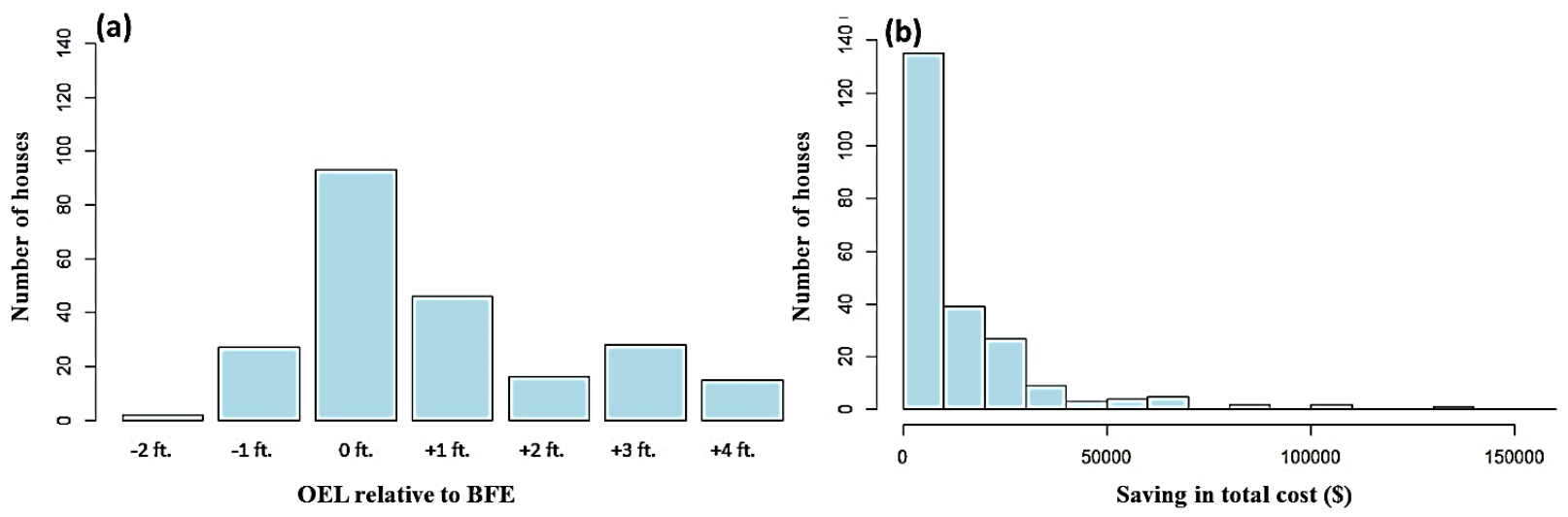

Figure 5. Same as in Fig. 4, except that the assumed lifespan for all houses is 50 years. 

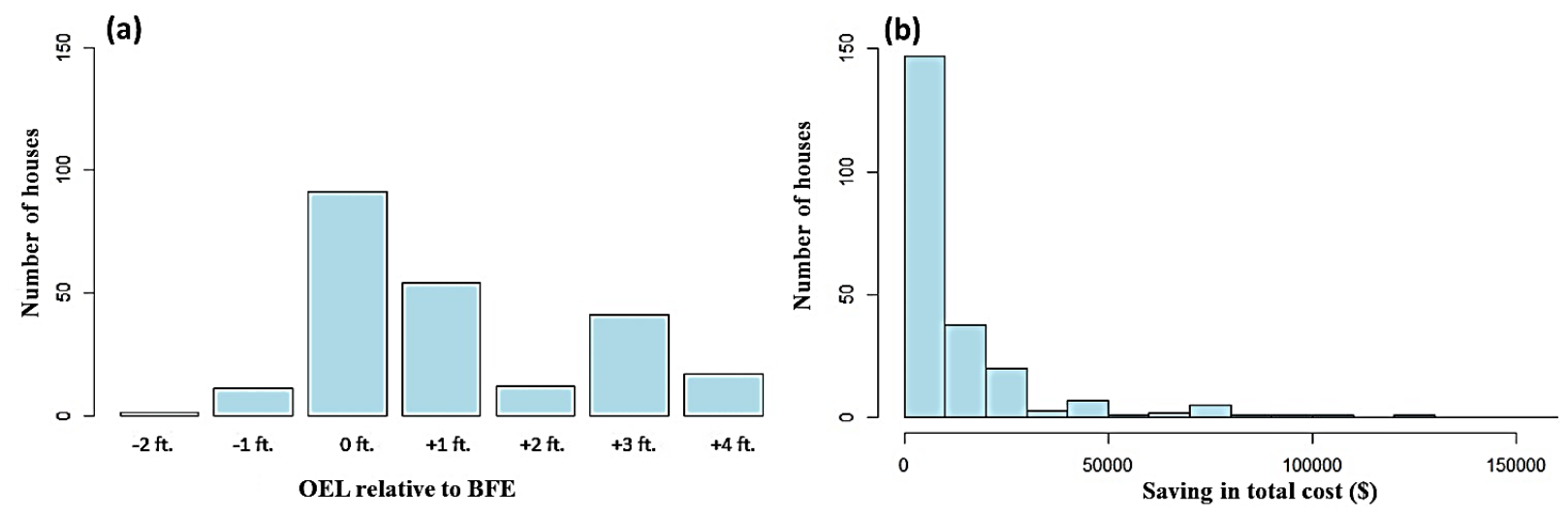

Figure 6. Same as in Fig. 4, except that the assumed lifespan for all houses is 100 years. 


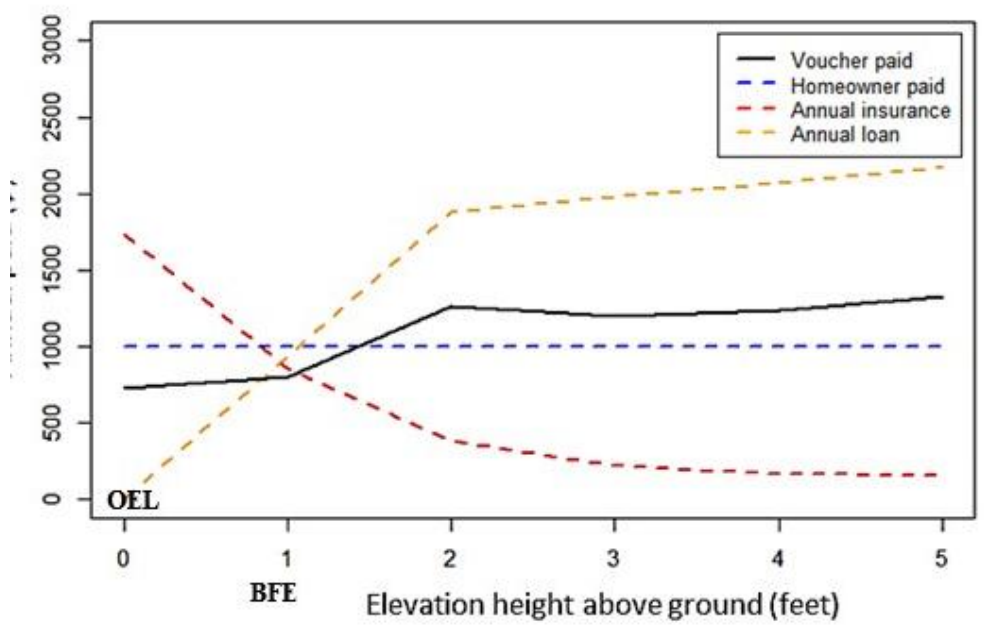

(a)

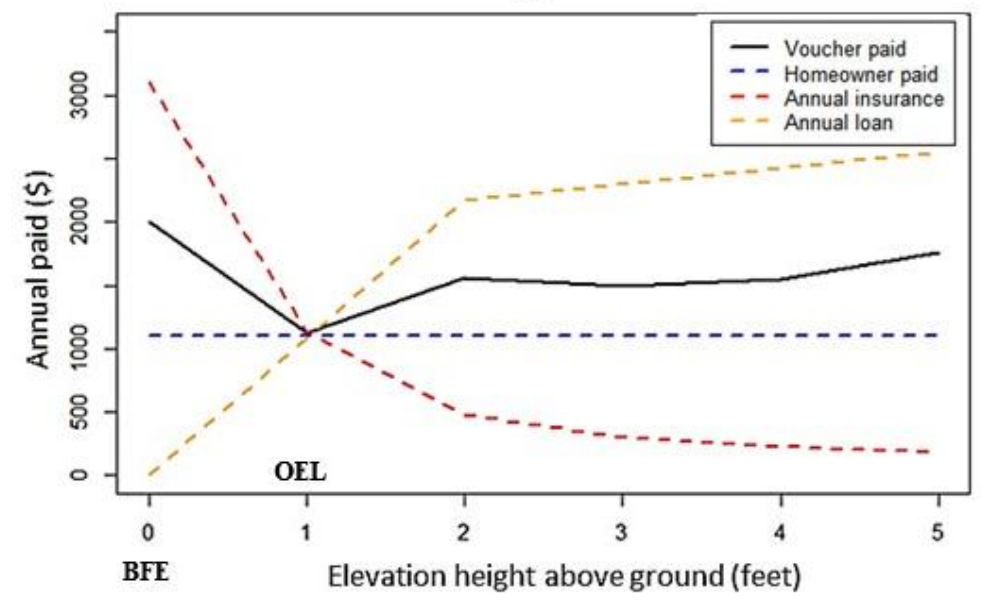

(b)

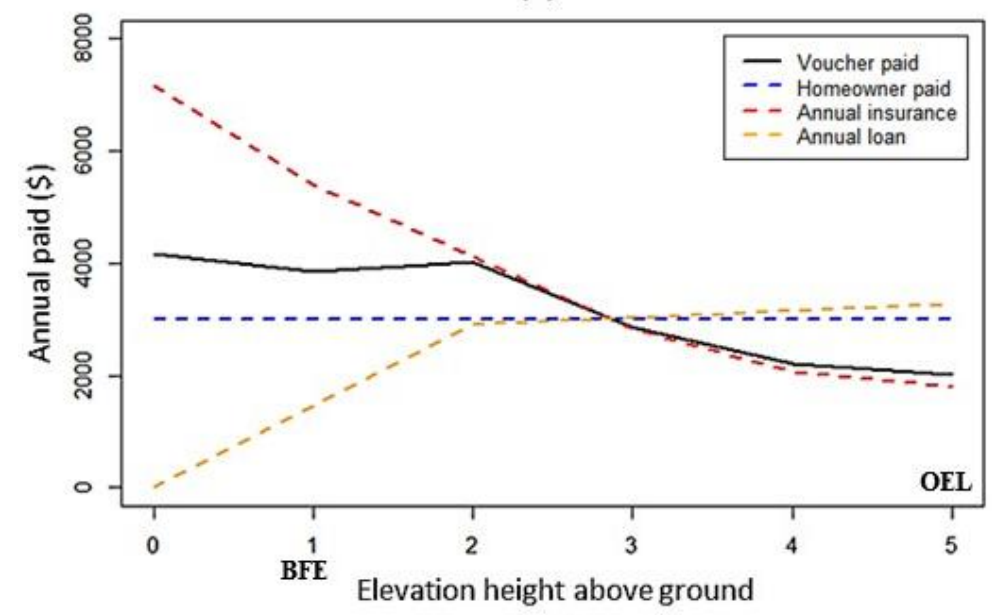

(c)

Figure 7. Variation with the elevation level of annual loan payment, insurance payment, affordable payment, and voucher payment for (a) House \#1, (b) House \#2, and (c) House \#3. Loan length is 30 years, loan interest rate is $3 \%$, and affordable fraction is $2 \%$. 

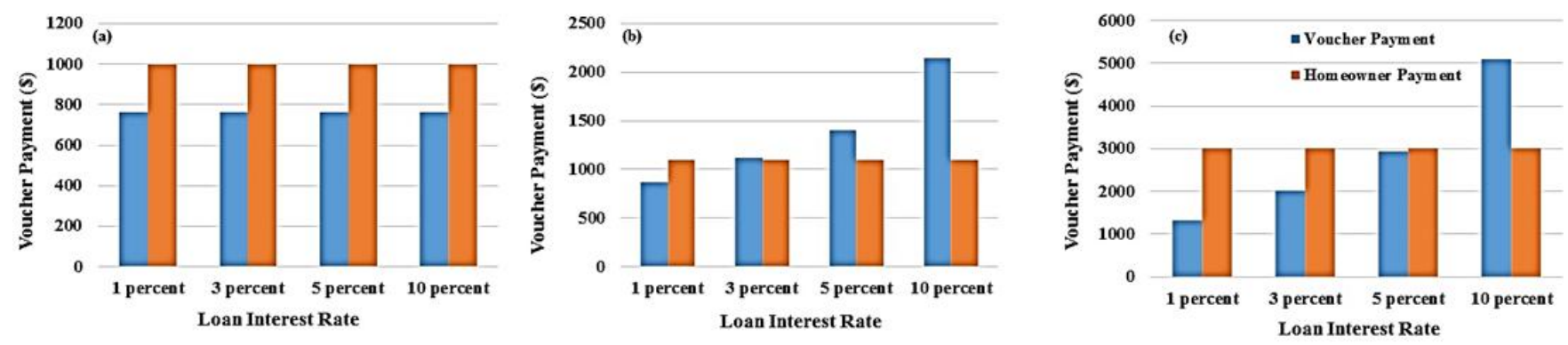

Figure 8. Variations of annual voucher and homeowner payment with different loan interest rates for (a) House \#1, (b) House \#2, and (c) House \#3. The loan length is 30 years; affordable fraction is $2 \%$.
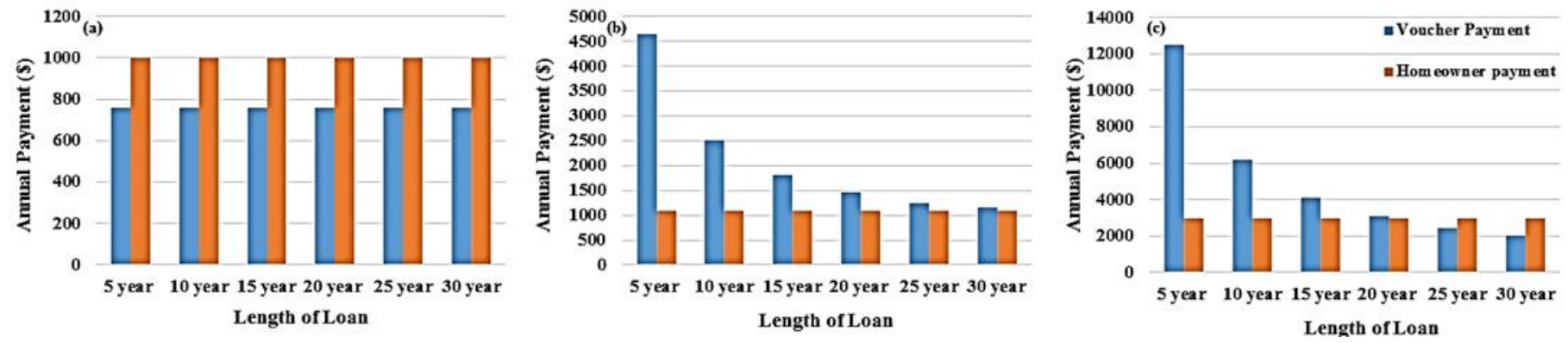

Figure 9. Variations of annual voucher and homeowner payment with different loan length for (a) House \#1, (b) House \#2, and (c) House \#3. Loan interest rate is 3\%; affordable fraction is $2 \%$. 


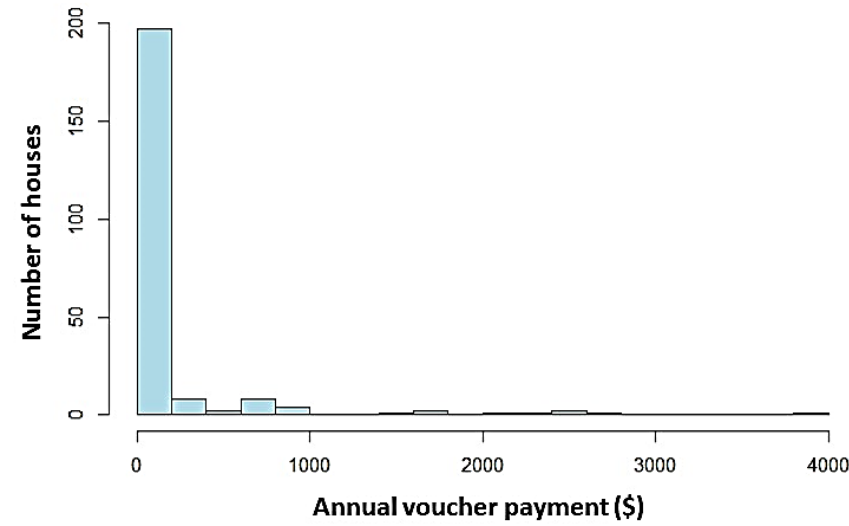

(a)

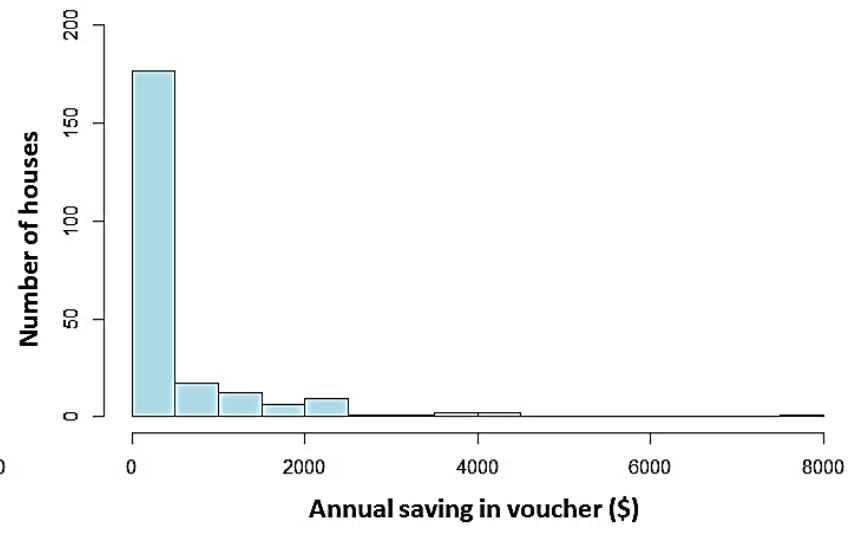

(b)

Figure 10. The distribution of (a) the annual voucher cost if the house is elevated to the OEL and (b) the resulting savings if the house is elevated to OELs, for all houses in the AE and VE zones in Ortley Beach. Lifespan of the houses is 30 years, discount interest rate is $3 \%$, loan length is 30 years, and loan interest rate is $3 \%$. 
Table 1. Characteristics of three sample buildings in Ortley Beach

\begin{tabular}{|l|c|l|c|c|c|}
\hline & Size $\left(\mathrm{ft}^{2}\right)$ & $\begin{array}{l}\text { Value } \\
(\$)\end{array}$ & $\begin{array}{l}\text { Ground Elevation } \\
(\mathrm{ft})\end{array}$ & Zone & BFE (ft) \\
\hline House \#1 & 1400 & 100,000 & 5 & AE & 6 \\
\hline House \#2 & 1500 & 117,500 & 6 & AE & 6 \\
\hline House \#3 & 2000 & 200,000 & 9 & VE & 10 \\
\hline
\end{tabular}

Table 2. The characteristics of houses in Ortley Beach, New Jersey in AE and VE zones

\begin{tabular}{|c|c|c|c|c|c|c|}
\hline Zone & $\begin{array}{c}\text { No. } \\
\text { Houses }\end{array}$ & $\begin{array}{c}\text { No. } \\
\text { Story }\end{array}$ & $\begin{array}{c}\text { Ground } \\
\text { Elevation }(\mathrm{ft})\end{array}$ & Value (\$) & Size (ft $\left.{ }^{2}\right)$ & $\begin{array}{c}\text { BFE } \\
(\mathrm{ft} .)\end{array}$ \\
\hline $\mathrm{AE}$ & 213 & $1-3$ & $4-8$ & $40000-200000$ & $463-3771$ & 6 \\
\hline $\mathrm{VE}$ & 14 & $1-3$ & $7-10$ & $38000-250000$ & $624-2785$ & 10 \\
\hline
\end{tabular}

